\title{
Magnetic Properties and Electrical Resistivity of $\mathrm{Zr}^{4+}$ Substituted Li-Zn Ferrite
}

\author{
${ }^{1}$ A.A. Sattar, ${ }^{1}$ H.M. El-Sayed, ${ }^{2}$ W.R. Agami and ${ }^{3}$ A.A. Ghani \\ ${ }^{1}$ Department of Basic Science, Faculty of Engineering, Misr University for Science and Technology \\ Cairo, Egypt \\ ${ }^{2}$ Department of Physics, Faculty of Science, Ain Shams University, 11566 Abbassia, Cairo, Egypt \\ ${ }^{3}$ Department of Science, College of Basic Education \\ Public Authority for Applied Education and Training, Kuwait
}

\begin{abstract}
The effect of Zr-substitution on the physical and magnetic properties of $\mathrm{Li}_{0.3+0.5 \mathrm{x}} \mathrm{Zn}_{0.4} \mathrm{Zr}_{\mathrm{x}} \mathrm{Fe}_{2.3-1.5 \mathrm{x}} \mathrm{O}_{4}$ ferrites ( $\mathrm{x}=0.0,0.01,0.02,0.03$ and 0.05$)$, prepared by the standard ceramic method, has been studied. It is found that the saturation magnetization increases up to $\mathrm{x}=0.02$ and then it decreases. On the other hand, the initial permeability increased while the Curie temperature remained almost constant with increasing $\mathrm{x}$. The behavior of coercivity and remanence ratio was discussed. The composition dependence of the dc electrical resistivity is found to support the hopping conduction mechanism.
\end{abstract}

Key words: Initial permeability, magnetization, hysteresis, ferrites, Li-Zn ferrites, magnetic properties, electrical resistivity

\section{INTRODUCTION}

Li-Zn ferrites are low cost materials and have important magnetic and electrical properties for technological applications. It is known that the intrinsic parameters of ferrites, such as magnetization, initial permeability, Curie temperature and resistivity depend on the chemical composition, heat treatment and type of additive or substituted ions ${ }^{[1]}$. Also, the rectangularity of B-H loop is also found to increase with increasing defects that hinder the magnetic domain wall motion in the grains ${ }^{[2]}$. The influence of additives, such as $\mathrm{Na}_{2} \mathrm{O}$, $\mathrm{CaO}, \mathrm{Sb}_{2} \mathrm{O}_{3}$ and $\mathrm{ZrO}_{2}$ on the structure, magnetic and electrical properties of $\mathrm{Li}-\mathrm{Zn}$ ferrites were previously reported $^{[1,3]}$. This work is devoted to study the effect of $\mathrm{Zr}^{4+}$ substitution, but not addition, on the magnetic properties and electrical resistivity of Li-Zn ferrite.

\section{MATERIALS AND METHODS}

Ferrite samples with the chemical formula $\mathrm{Li}_{0.3+0.5 \mathrm{x}} \mathrm{Zn}_{0.4} \mathrm{Zr}_{\mathrm{x}} \mathrm{Fe}_{2.3-1.5 \mathrm{x}} \mathrm{O}_{4}(\mathrm{x}=0.0,0.01,0.02,0.03$ and $0.05)$ were prepared by the usual standard ceramic method. High purity oxides, $99.99 \%$, of $\mathrm{ZnO}$ and $\mathrm{Fe}_{2} \mathrm{O}_{3}$ with $\mathrm{Li}_{2} \mathrm{CO}_{3}$ and $\mathrm{ZrO}_{2}$ were mixed together according to their molecular weight ratios. The mixture of each sample was ground to a very fine powder and then presintered at $800{ }^{\circ} \mathrm{C}$ for $6 \mathrm{~h}$. The presintered mixture was ground again and pressed at room temperature, under a pressure of $7 \times 10^{8} \mathrm{~Pa}$, into tablet and toroidal forms. They were finally sintered at $1050{ }^{\circ} \mathrm{C}$ for $3 \mathrm{~h}$ and then slowly cooled to room temperature. X-ray diffraction patterns were performed using a diffractometer of type $\mathrm{X}^{\top}$ Pert Graphics and identified with $\mathrm{Cu} \mathrm{K} \mathrm{K}_{\alpha}$ radiation. The theoretical X-ray density, $\mathrm{d}_{\mathrm{x}}$, of the samples was calculated according to the formula $\left(d_{x}=8 \mathrm{M} / \mathrm{Na}^{3}\right)$ where $\mathrm{M}$ is the molecular weight, $\mathrm{N}$ is Avogadro's number and $\mathrm{a}$ is the lattice parameter. The density, $d$, of each sample was measured in bidistilled water using Archimedes' principle. The porosity percentage $\mathrm{P}(\%)$ was calculated according to the relation $\mathrm{P}=100\left[1-\left(\mathrm{d} / \mathrm{d}_{\mathrm{x}}\right)\right] \%$. The magnetization $\mathrm{M}$, at room temperature, was measured using the vibrating sample technique. The magnetizing field ranged from 0.0 up to 1.4 Tesla. A toroidal sample of each composition was used as a transformer core for measuring the initial permeability, $\mu_{i}$, which was measured as a function of temperature at a constant frequency $\mathrm{f}=10 \mathrm{KHz}$. The value of $\mu_{\mathrm{i}}$ was calculated using Poltinnikov`s formula ${ }^{[4]}, V_{s}=K \mu_{i}$, where $V_{s}$ is the induced voltage in the secondary coil and $K=\mu_{o} n_{p} n_{s} I_{p} A \omega / L ; n_{p}$ and $n_{s}$ are the number of turns of the primary and secondary coils respectively, $I_{p}$ is the current in the primary coil, A is the cross-sectional area of the sample, $\omega$ is the angular frequency and $\mathrm{L}$ is the average path of the magnetic flux. Moreover, the coercive field and remanence were determined from the hysteresis loop. The disc samples were used for the electrical resistivity measurements at room temperature. Each sample was inserted between two platinum electrodes where $\mathrm{In}-\mathrm{Hg}$ was used as a contact material.

Corresponding Author: Prof. Dr. A.A.Sattar, Department of Basic Science, Faculty of Engineering, Misr University for Science and Technology, $6^{\text {th }}$ October City, Cairo, Egypt 


\section{RESULTS AND DISCUSSION}

X-ray analysis: The X-ray diffraction patterns, Fig. 1, showed that all investigated samples have single phase of cubic spinel structure. The d-spacing for each peak was recorded automatically and then the lattice parameter (a) was calculated using the relation $\mathrm{a}=\mathrm{d}_{\mathrm{hkl}}\left(\mathrm{h}^{2}+\mathrm{k}^{2}+\mathrm{l}^{2}\right)^{1 / 2}$

where $h, k$ and 1 are the Miller indices of each plane. The values of the lattice parameters obtained for each reflected plane are plotted against the function $F(\theta)$ where $F(\theta)=(1 / 2)\left[\left(\cos ^{2} \theta / \sin \theta\right)+\left(\cos ^{2} \theta / \theta\right)\right] ; \theta$ is the Bragg's angle. Straight lines were obtained and the accurate values of $\mathrm{a}(\AA)$ were determined from the extrapolation of these lines to $(\theta)=0^{[5]}$. The variation of the lattice parameter $\mathrm{a}(\AA)$ as a function of $\mathrm{Zr}$ concentration (x) is shown in Fig. 2. It can be observed that the lattice parameter is more or less constant within the experimental error. The constancy of the lattice parameter with $\mathrm{Zr}$-concentration could be explained as follows: According to the ionic radii $\left(\mathrm{r}_{\mathrm{Li} 1+}=0.68 \AA\right.$, $\mathrm{r}_{\mathrm{Zr} 4+}=0.79 \AA$ and $\mathrm{r}_{\mathrm{Fe} 3+}=0.64 \AA$ ) the lattice parameter is expected to increase with increasing $\mathrm{Zr}$-concentration. However, the attraction force of the oxygen ions for the tetravalent ions $\left(\mathrm{Zr}^{4+}\right)$ is larger than those for monovalent $\left(\mathrm{Li}^{1+}\right)$ and trivalent $\left(\mathrm{Fe}^{3+}\right)$ ions. Thus the bond length and hence the lattice parameter must decrease. Therefore, one concludes that the competition between ionic radii and attraction forces is responsible for the observed constancy of the lattice parameter. It is noticed that the value of the lattice parameter (a) for the unsubstituted sample $\mathrm{Li}_{0.3} \mathrm{Zn}_{0.4} \mathrm{Fe}_{2.3} \mathrm{O}_{4} \quad(8.3817 \AA)$ compares well with those reported earlier $\left(8.378 \AA^{[1,6]}\right.$, $\left.8.380 \AA^{[3]}\right)$. In contrast to our results, the lattice parameter for additive samples was found to increase with $\mathrm{x}^{[1,6]}$.

\section{Magnetic properties}

Magnetization: Figure 3 shows the variation of magnetization $\mathrm{M}(\mathrm{emu} / \mathrm{g})$ versus the applied magnetic field $\mathrm{H}(\mathrm{T})$ at room temperature. Behaving normally, the magnetization increases with increasing the applied magnetic field and attains its saturation value for higher field. The saturation magnetization $M_{s}$ for each sample was determined by extrapolation of the magnetization curve to $\mathrm{H}=0$. The dependence of $\left(\mathrm{M}_{\mathrm{s}}\right)$ on the $\mathrm{Zr}$ concentration ( $\mathrm{x}$ ) is illustrated in Fig. 4. It is noticed that $\mathrm{M}_{\mathrm{s}}$ increases rapidly with (x) and reaches its highest value at $\mathrm{x} \approx 0.02$. Further increase of $\mathrm{Zr}$ concentration leads $M_{s}$ to decrease. Such a result could be discussed assuming the following cation distribution: $\left(\mathrm{Zn}_{0.4} \mathrm{Zr}_{\mathrm{x}-\mathrm{t}} \mathrm{Fe}_{0.6-\mathrm{x}+\mathrm{t}}\right)\left[\mathrm{Li}_{0.3+0.5 \mathrm{x}} \mathrm{Zr}_{\mathrm{t}} \mathrm{Fe}_{1.7-0.5 \mathrm{x}-\mathrm{t}}\right] \mathrm{O}_{4}$

where the brackets ( ) and [ ] denote A- and B- sites respectively. This cation distribution is based on the following facts:

1. $\mathrm{Li}^{1+}$ ions have a strong preference to occupy the $\mathrm{B}-$ site ${ }^{[7]}$ while $\mathrm{Zn}^{2+}$ ions have a strong preference to occupy the A-site ${ }^{[8]}$.

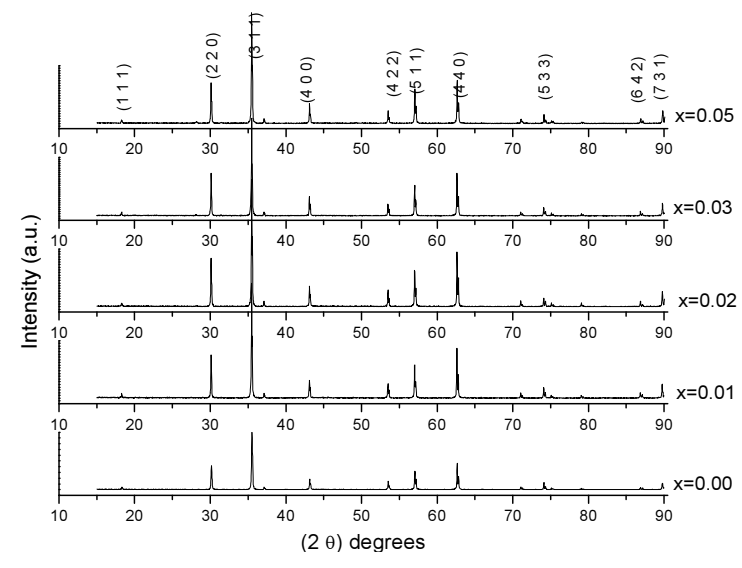

Fig. 1: X-ray diffraction patterns of $\mathrm{Li}_{0.3+0.5 \mathrm{x}} \mathrm{Zn}_{0.4} \mathrm{Zr}_{\mathrm{x}} \mathrm{Fe}_{2.3-1.5 \mathrm{x}}$

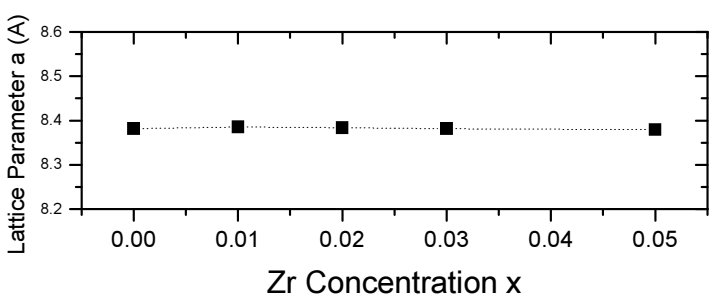

Fig. 2: The variation of the lattice parameter a (z) with Zr-concentration (x)

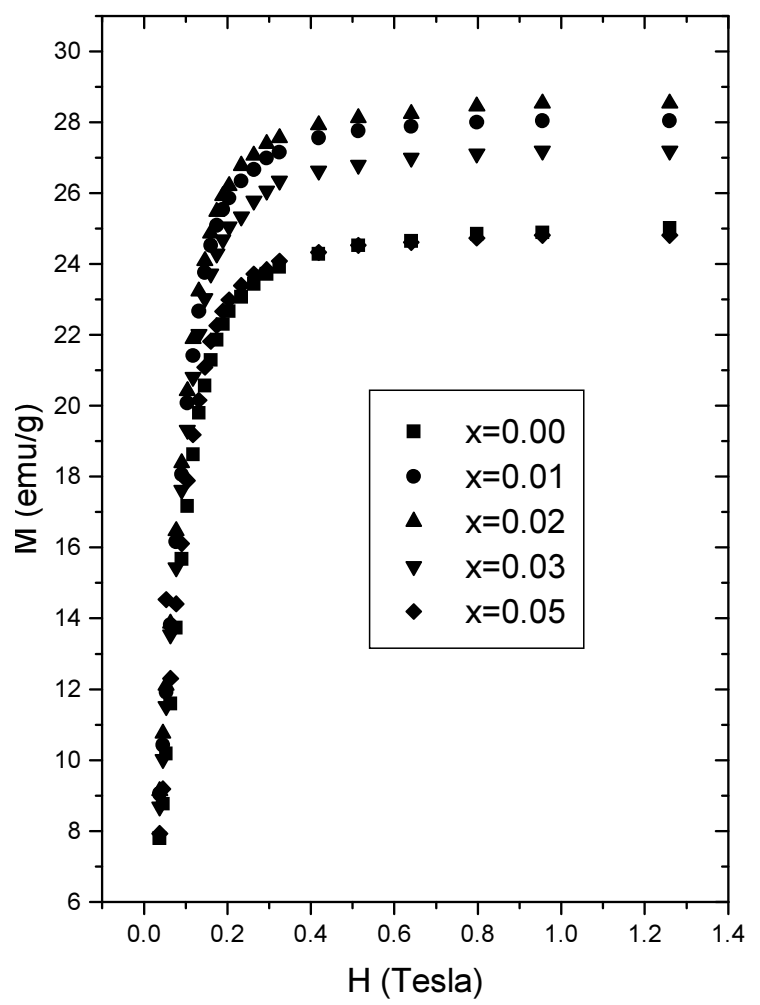

Fig. 3: The magnetization (emu/g) versus the applied magnetic field $\mathrm{H}(\mathrm{T})$ 
2. For $\mathrm{Zr}$-ion distribution, it was reported that $\mathrm{Zr}^{4+}$ ions first enter the A-site for low concentration and then subdivide between $\mathrm{A}$ - and $\mathrm{B}$-sites for higher concentrations ${ }^{[9]}$. As $M_{s}$ is given by $\left(M_{s}=M_{B}-M_{A}\right)$ where $M_{A}$ and $M_{B}$ are the magnetizations of $A$ - and $\mathrm{B}$-sites respectively, thus the general formula of the saturation magnetization could be written as

$\mathrm{M}_{\mathrm{s}}=(1.1+0.5 \mathrm{x}-2 \mathrm{t}) \cdot 5 \mu_{\mathrm{B}}$

where $\mu_{B}$ is Bohr magneton. For $x \leq 0.02$, where $t$ is assumed equals to zero, $M_{\mathrm{s}}$ is given by

$\mathrm{M}_{\mathrm{s}}=(1.1+0.5 \mathrm{x}) .5 \mu_{\mathrm{B}}$

According to equation (2), $M_{s}$ increases with $x$ in this range. For $x>0.02$ and $t>0, M_{s}$ is given by the general formula, equation (1), which shows that $M_{s}$ decreases with $x$ if $t>0.2 x$.

It is noted that for additive samples the magnetization decreases more slightly than the substituted ones ${ }^{[6]}$.

Initial permeability: Figure 5 shows the variation of the initial permeability $\mu_{\mathrm{i}}$ with temperature for the series $\mathrm{Li}_{0.3+0.5 \mathrm{x}} \mathrm{Zn}_{0.4} \mathrm{Zr}_{\mathrm{x}} \mathrm{Fe}_{2.3-1.5 \mathrm{x}} \mathrm{O}_{4} \quad(\mathrm{x}=0.0,0.01,0.02$, 0.03 and 0.05$)$. It is seen that $\mu_{\mathrm{i}}$ increases with temperature up to Curie temperature $T_{c}$. Near $T_{c}$ there is a sharp drop in $\mu_{\mathrm{i}}$. This result could be explained according to Globus relation ${ }^{[10]}$ which is given by $\mu_{\mathrm{i} \alpha}\left(\mathrm{M}_{\mathrm{s}}^{2} \mathrm{D} / \mathrm{K}_{1}^{1 / 2}\right)$

where $\mathrm{D}$ is the average grain size and $\mathrm{K}_{1}$ is the anisotropy constant. According to this relation, the dependence of $\mu_{\mathrm{i}}$ on temperature results from the temperature dependence of $\mathrm{M}_{\mathrm{s}}$ and $\mathrm{K}_{1}$ assuming that $\mathrm{D}$ is constant for the same composition. It is known that the anisotropy field usually decreases much faster with temperature than $\mathrm{M}_{\mathrm{s}}{ }^{[11]}$ which leads to an initial increase in $\mu_{\mathrm{i}}$. Near $\mathrm{T}_{\mathrm{c}}, \mathrm{M}_{\mathrm{s}}$ drops suddenly to zero which accounts for the rapid decrease of $\mu_{i}$ at $T=T_{c}$. The composition dependence of $\mu_{\mathrm{i}}$, at room temperature and porosity are represented in Fig. 6 . It is clear that all substituted samples have higher $\mu_{i}$ than the unsubstituted one. Moreover, $\mu_{\mathrm{i}}$ attains a maximum value at $\mathrm{Zr}$-concentration $\mathrm{x}=0.01$. Similar results were reported for additive samples ${ }^{[1,6]}$. Furthermore, it is obvious that the initial permeability has an inverse relation with the porosity which ensures that the porosity hinders the domain wall motion ${ }^{[12]}$. The behavior of $\mu_{\mathrm{i}}$ with $\mathrm{Zr}$ - concentration (x) could be explained using Globus relation as follows:

For $x \leq 0.01$, both $M_{s}$ and porosity enhance $\mu_{i}$ to increase where $M_{s}$ increases and the porosity decreases. For $\mathrm{x}>0.01$, the increasing of the porosity and decreasing of $\mathrm{D}^{[1,13]}$ play a role in decreasing $\mu_{\mathrm{i}}$. Moreover, for $\mathrm{x}>0.02$, the decrease of $\mathrm{M}_{\mathrm{s}}$ gives further contribution in decreasing $\mu_{\mathrm{i}}$. On the Other hand, as D decreases with increasing $\mathrm{x}$, the intergranular porosity decreases which explains the decrease in porosity for $x$ $=0.01$. For $\mathrm{x} \geq 0.01$, the larger ions of $\mathrm{Zr}^{4+}$ and $\mathrm{Li}^{1+}$ that enter the grains cause the increase in the intragranular

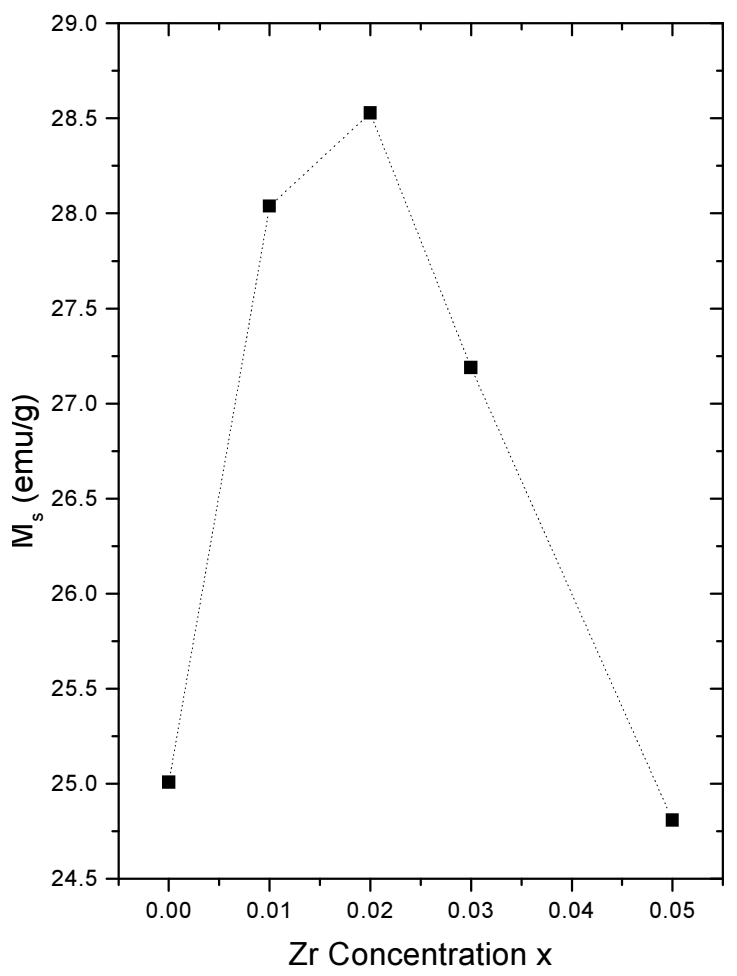

Fig. 4: The variation of saturation magnetization $M_{s}$ (emu/g) with Zr-concentration (x)

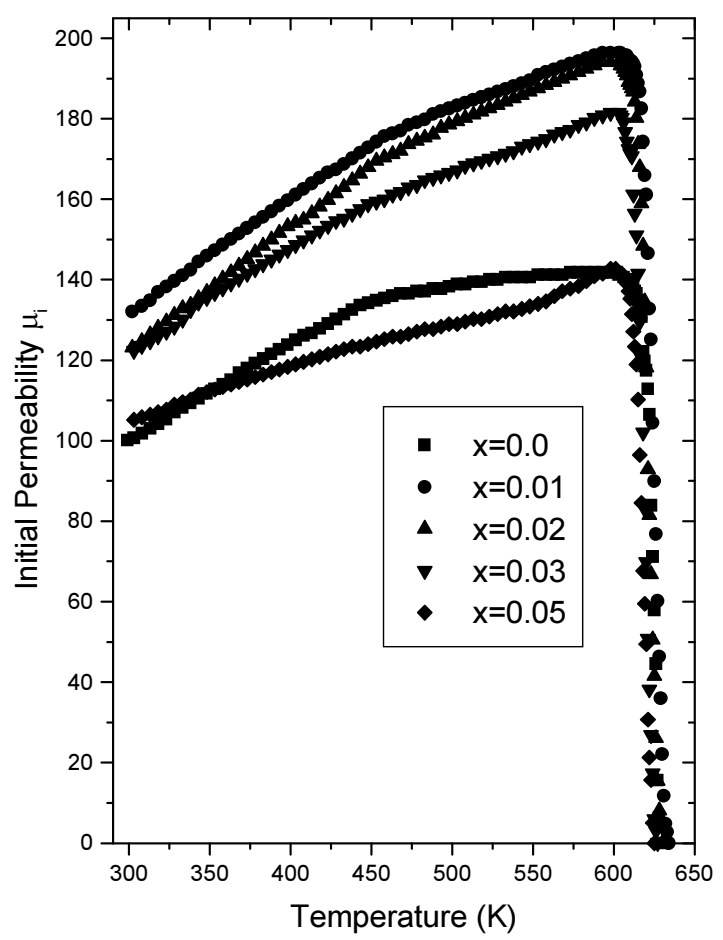

Fig. 5: The temperature dependence of the initial permeability $\mu_{1}$ for different Zrconcentrations $(\mathrm{x})$

porosity. Such an increase tends to be dominant and explains the increase of porosity in this range. 
Curie temperature: The values of Curie temperature $\left(T_{c}\right)$ were determined from the interception of the extrapolation of the linear part at the sudden decrease of $\mu_{\mathrm{i}}$ of Fig. 6 with the temperature axis for all investigated samples. The values of $T_{c}$ and the rate of decrease of $\mu_{\mathrm{i}}$ (slope of the linear part) are given in Table 1.

The Table illustrates that $T_{c}$ is almost constant $(628$ $\pm 4 \mathrm{~K}$ ) while it was reported that it decreases for additive samples ${ }^{[6]}$. Such a constancy may be discussed as follows. It is known that, in ferrites, $T_{c}$ depends mainly on the A-B interaction which in turn is affected by the following factors:

1. The magnitude of the magnetic moments in A- and B-sites. In our studied system the only moments are those of $\mathrm{Fe}^{3+}$ ion.

2. The relative concentration of the moments on both sites $\left(\mathrm{M}_{\mathrm{A}} / \mathrm{M}_{\mathrm{B}}\right)$. In our investigated samples, according to the assumed cation distribution, the minimum and maximum values of $\left(\mathrm{M}_{\mathrm{A}} / \mathrm{M}_{\mathrm{B}}\right)$ are 0.343 and 0.353 respectively. Thus $\left(\mathrm{M}_{\mathrm{A}} / \mathrm{M}_{\mathrm{B}}\right)$ is almost constant and hence does not affect $T_{c}$.

3. The distance between the A- and B-sites. From Fig. 2 , it was found that the change of the lattice parameter with $\mathrm{Zr}$-concentration, $0.006 \AA$, is so small that it does not affect $\mathrm{T}_{\mathrm{c}}$. Thus, according to the above factors, $T_{c}$ tends to be almost constant which we have found experimentally.

Also from Table 1, one can notice that the slope of the linear part of $\mu_{\mathrm{i}}(\mathrm{T})$ curve, at the sudden decrease of $\mu_{i}$, increases for $\mathrm{x}=0.01$, then for $\mathrm{x}>0.01$ it decreases with increasing $\mathrm{Zr}^{4+}$ concentration. Previous studies have reported that the value of this slope could be considered as a good indicator of the sample homogeneity ${ }^{[10]}$. It means that the higher the slope the higher the homogeneity. Thus, one can conclude that the homogeneity increases for $\mathrm{x}=0.01$ and then decreases for $x>0.01$. Such a result is in agreement with the behavior of the porosity with $\mathrm{Zr}$-concentration (Fig. 6).

Coercivity and squareness: The variations of the coercive field $H_{c}$ and the remanence ratio $\left(B_{r} / B_{s}\right)$, which expresses the squareness of the hysteresis loop, for all $\mathrm{Zr}$ - concentrations ( $\mathrm{x}$ ) at a field $\mathrm{H}=340 \mathrm{~A} / \mathrm{m}$ are given in Table 2.

From Table 2, it is obvious that $\mathrm{H}_{\mathrm{c}}$ decreased for the sample with $\mathrm{x}=0.01$ then it increased for $\mathrm{x}>0.01$. This behavior is similar to that of the porosity. As the porosity increases, then higher field is needed to push the domain wall i.e. $\mathrm{H}_{\mathrm{c}}$ increases and vice versa. Furthermore, the saturation magnetization $M_{s}$ plays a role in the behavior of $\mathrm{H}_{\mathrm{c}}$ through Brown's relation ${ }^{[14]}$ which is given by

$\mathrm{H}_{\mathrm{c}} \geq\left(2 \mathrm{~K}_{1} / \mu_{\mathrm{o}} \mathrm{M}_{\mathrm{s}}\right)$
According to this relation $\mathrm{H}_{\mathrm{c}}$ is inversely proportional to $\mathrm{M}_{\mathrm{s}}$ which we have found experimentally.

Table 1: The values of $\mathrm{T}_{\mathrm{c}}(\mathrm{K})$ and rate of decrease of $\mu_{\mathrm{i}}$ with $\mathrm{Zr}$ concentration

\begin{tabular}{llc}
\hline Zr-Conc. $(\mathrm{x})$ & $\mathrm{T}_{\mathrm{c}}(\mathrm{K})$ & Rate of decrease of $\mu_{\mathrm{i}}\left(\mathrm{K}^{-1}\right)$ \\
\hline 0.00 & 628 & -15.85 \\
0.01 & 631 & -16 \\
0.02 & 627 & -14.97 \\
0.03 & 624 & -14.83 \\
0.05 & 624 & -12.67 \\
\hline
\end{tabular}

Table 2: The values of $H_{c}(A / m),\left(B_{r} / B_{s}\right)$ and $\rho(\Omega . c m)$ with $Z r-$ concentration $(\mathrm{x})$

\begin{tabular}{lccc}
\hline Zr-Conc. $(\mathrm{x})$ & $\mathrm{H}_{\mathrm{c}}(\mathrm{A} / \mathrm{m})$ & $\left(\mathrm{B}_{\mathrm{r}} / \mathrm{B}_{\mathrm{s}}\right)$ & $\rho(\Omega . \mathrm{cm}) \times 10^{7}$ \\
\hline 0.00 & 92 & 0.17 & 3.6 \\
0.01 & 82.7 & 0.15 & 4.5 \\
0.02 & 86.5 & 0.18 & 15.9 \\
0.03 & 88.9 & 0.19 & 21.9 \\
0.05 & 98.4 & 0.22 & 33.9 \\
\hline
\end{tabular}

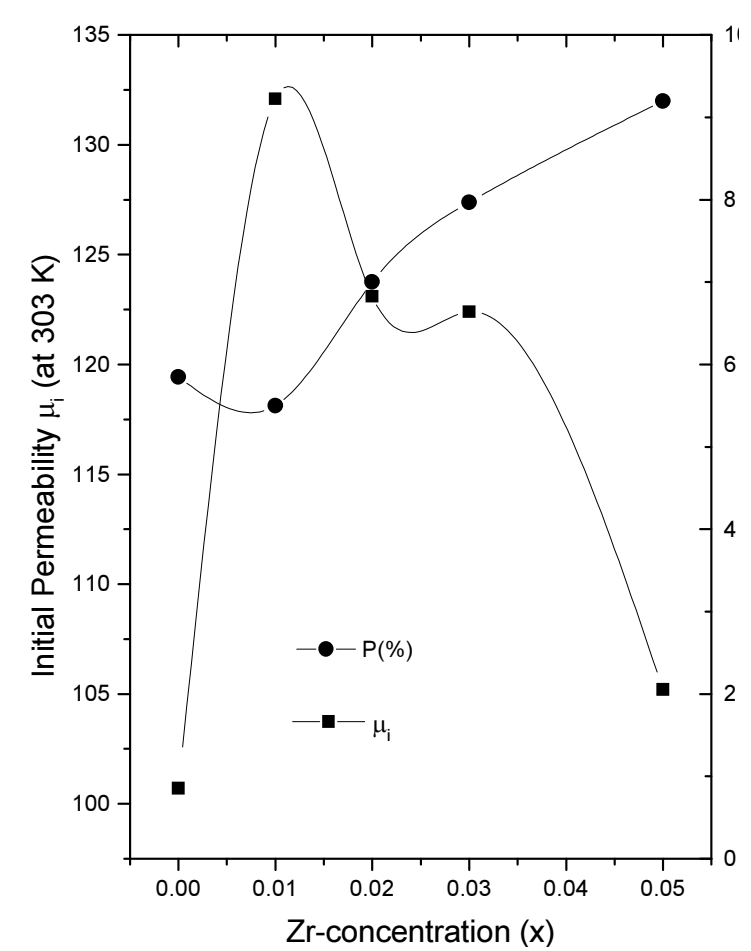

Fig. 6: The variation of the initial permeability $\left(\mu_{1}\right)$, at room temperature and porosity $\mathrm{p}(\%)$ with $\mathrm{Zr}$ concentration $(\mathrm{x})$

Moreover, Table 2 shows also that the ratio $\left(\mathrm{B}_{\mathrm{r}} / \mathrm{B}_{\mathrm{s}}\right)$ behaves similar to $H_{c}$. The behavior of the ratio $\left(B_{r} / B_{s}\right)$ could be discussed according to the fact that the remanance $B_{r}$ is directly proportional to the porosity ${ }^{[15]}$ while $B_{s}$ is directly proportional to $M_{s}$. Increasing $x$ from 0.0 to 0.01 , the porosity decreases and $M_{s}$ increases. This leads $\left(\mathrm{B}_{\mathrm{r}} / \mathrm{B}_{\mathrm{s}}\right)$ to decrease. For higher values of $x$, the porosity increases while $M_{s}$ decreases. This causes more increase of $B_{r} / B_{s}$. 
Resistivity at room temperature: The values of $\mathrm{dc}$ resistivity $(\rho)$ of all investigated samples, at room temperature, are given in Table 2 . The table indicates that the dc resistivity ( $\rho$ ) increases with increasing $\mathrm{Zr}$ concentration (x). Previous studies showed that ( $\rho$ ) increases slightly for additive samples ${ }^{[1,6]}$. Our result could be discussed as follows. According to the chemical formula of our investigated series, $\mathrm{Li}_{0.3+0.5 \mathrm{x}} \mathrm{Zn}_{0.4} \mathrm{Zr}_{\mathrm{x}} \mathrm{Fe}_{2.3-1.5 \mathrm{x}} \mathrm{O}_{4}$, as Zr-concentration $\mathrm{x}$ increases, the $\mathrm{Fe}$-concentration decreases. Thus the chance of formation of $\mathrm{Fe}^{2+}$ ions minimizes. So the probability of hopping between $\mathrm{Fe}^{2+}$ and $\mathrm{Fe}^{3+}$ decreases and hence the resistivity increases. Moreover, it was reported that the tetravalent ion is able to form stable bonds with $\mathrm{Fe}^{2+}$ ions ${ }^{[16]}$. Since $\mathrm{Zr}^{4+}$ is tetravalent, it localizes $\mathrm{Fe}^{2+}$ ions that may be formed during sintering process. This localization hinders the Verwey-de Boer mechanism between $\mathrm{Fe}^{2+}$ and $\mathrm{Fe}^{3+}$ ions, resulting in an increase of the resistivity ${ }^{[16]}$. Furthermore, the increasing porosity in the range $x \geq 0.01$ enhances the rapid increase of resistivity. Finally, the decrease of the grain size with increasing $\mathrm{Zr}^{4+}$ concentration, as previously reported, implies an increase in the grain boundary thickness which leads the resistivity to increase.

\section{CONCLUSION}

* It was found that substitution of nonmagnetic $\left(\mathrm{Zr}^{4+}\right)$ ions in mixed $\mathrm{Li}-\mathrm{Zn}$ ferrite leads to an increase in the saturation magnetization $\left(M_{s}\right)$ to a maximum value at concentration $x=0.02$. This behavior was explained using the cation distribution between $(\mathrm{A})$ and $[\mathrm{B}]$ sites.

* The initial permeability $\left(\mu_{\mathrm{i}}\right)$ at room temperature attains also maximum value at $\mathrm{Zr}$-concentration $\mathrm{x}=0.01$. This behavior was explained using Globus relation.

* The values of coercivity $\left(\mathrm{H}_{\mathrm{c}}\right)$ and remanence ratio $\left(\mathrm{B}_{\mathrm{r}} / \mathrm{B}_{\mathrm{s}}\right)$ for the investigated samples reached a minimum at $\mathrm{x}=0.01$. This change was explained using Brown`s relation.

* It is found that increase of concentration of $\mathrm{Zr}^{4+}$ up to $\mathrm{x}=0.05$ has negligible effect on values of the lattice parameter and Curie temperatures.

* The dc electrical resistivity showed a gradual increase by about one order of magnitude. This is attributed to the fact that $\mathrm{Zr}^{4+}$ ions localize $\mathrm{Fe}^{2+}$ ions and this localization hinders the Verwey-de Boer hopping mechanism between $\mathrm{Fe}^{2+}$ and $\mathrm{Fe}^{3+}$ ions.

\section{REFERENCES}

1. Rezlescu, N. and E. Rezlescu, 1995. The influence of additives on the material parameters of Li-Zn ferrites. Phys. Stat. Sol. (a), 147: 553-562.
2. Kim, H.T. and H.B. Im, 1982. Effects of $\mathrm{Bi}_{2} \mathrm{O}_{3}$ and $\mathrm{Nb}_{2} \mathrm{O}_{5}$ on the magnetic properties of $\mathrm{Ni}-\mathrm{Zn}$ ferrites and lithium ferrites. IEEE Trans. on Magnetics, 18: 1541-1543.

3. Edelio, B., T.le Mercier and M. Quarton, 1995. Microstructure and physicochemical studies of pure and zinc-substituted lithium ferrites sintered above $1000^{\circ}$ C. J. Am. Ceram. Soc., 78: 365-368.

4. Poltinnikov, S.A., 1966. Some magnetic properties of nickel-cadmium ferrite. Sov. Phys. Solid Stat., 8: 1144-1149.

5. Cullity, B.D., 1959. Elements of X-ray diffraction. Published by Addison-Wesley Publishing Company, Inc., Second Printing, pp: 330.

6. Rezlescu, N. and E. Rezlescu, 1996. Effects of addition of $\mathrm{Na}_{2} \mathrm{O}, \mathrm{Sb}_{2} \mathrm{O}_{3}, \mathrm{CaO}$ and $\mathrm{ZrO}_{2}$ on the properties of lithium zinc ferrite. J. Am. Ceram. Soc., 79: 2105-2108.

7. White, G.O. and C.E. Patton, 1978. Magnetic properties of lithium ferrite microwave materials. J. Magn. Magn. Mater., 9: 299-317.

8. Xu, Z.C., 2003. Magnetic anisotropy and Mössbauer spectra in disordered lithium-zinc ferrites. J. Appl. Phys., 93: 4746-4749.

9. Das, A.R., V.S. Ananthan and D.C. Khan, 1985. Lattice parameter variation and magnetization studies on titanium-, zirconium- and tin-substituted nickel-zinc ferrites. J. Appl. Phys., 57: 4189-4191.

10. Globus, A., H. Pascard and V.J. Cagan, 1977. Distance between magnetic ions and fundamental properties in ferrites. J. Phys., 38: C1-163-168.

11. Sankpal, A.M., S.V. Kakatkar, N.D. Chaudhari, R.S. Patil and S.S. Suryavanshi, 1998. Initial permeability studies on $\mathrm{Al}^{3+}$ and $\mathrm{Cr}^{3+}$ substituted $\mathrm{Ni}-\mathrm{Zn}$ ferrites. J. Mater. Sci.,: Materials in Electronics, 9: 173-179.

12. Jain, G.C., B.K. Das, R.S. Khanduja and S.C. Gupta, 1976. Effect of intragranular porosity of initial permeability and coercive force in a manganese zinc ferrite. J. Mater. Sci., 11: 13351338.

13. Rezlescu, E., N. Rezlescu, C. Pasnicu, M.L. Craus and D.D. Popa, 1992. The influence of additives on the properties of $\mathrm{Ni}-\mathrm{Zn}$ ferrite used in magnetic heads. J. Magn. Magn. Mater., 117: 448-454.

14. Coey, J.M.D., 1996. Rare Earth Permanent Magnetism. Published by John Wiley and Sons, New York, pp: 220.

15. Bozorth, R.M., 1963. Ferromagnetism. Published by Van Nostrand Company, Inc. Princeton, New Jersey, pp: 824.

16. Rana, C.P., J.S. Baijal and P. Kishan, 1983. Electrical conductivity of Ni-Zn ferrites doped with $\mathrm{Ti}^{4+}$ ions. J. Less- Common Metals, 165: 257-261. 